general method with appropriate modifications for particular vitamins. A method for the biological evaluation of protein quality is also included in this section.

The actual amount of material in this book is continually increasing, and in order, therefore, to keep the size within reasonable bounds the style of this new edition has been changed to a larger page divided into two columns. The new format is easier to read, and I welcome the change, especially as it means that further abbreviations of the text have thus been avoided.

H. V. HART

\section{CONTROLLED THERMONUCLEAR REACTIONS}

\section{Plasma Physics and Thermonuclear Research}

Vol. 1. Edited by G. Longmire, James L. Tuck and W. B. Thompson. (Progress in Nuclear Energy, Series XI.) Pp. vii $+612+x i i$. (London and New York: Pergamon Press, 1959.) 105s. net; 15 dollars.

\section{Nuclear Fusion}

Edited by Prof. William P. Allis (Second Geneva Series on the Peaceful Uses of Atomic Energy.) Pp. viii +488. (Princeton, N.J. : D. Van Nostrand Company, Inc.; London: D. Van Nostrand Company, Ltd., 1960.) 12.50 dollars ; $94 s$.

\section{Controlled Thermonuclear Reactions}

An Introduction to Theory and Experiment. By Samuel Glasstone and Ralph H. Lovberg. Prepared under the auspices of the Office of Technical Inform ation, United States Atomic Energy Commission. Pp. xvi +523. (Princeton, N.J.: D. Van Nostrand Company, Inc.; London : D. Van Nostrand Company, Ltd., 1960.) 5.60 dollars; $42 s$.

$$
T^{1}
$$

THE opening in September 1958 of the second International Conference on the Peaceful Uses of Atomic Energy will go down in scientific history as the day the dam burst. It was then that the veil of secrecy was removed from some six years of intensive study in the United States, the United Kingdom and the U.S.S.R. of what is now generally called nuclear fusion. The views and results of hundreds of scientific workers were suddenly thrown. open for free discussion, and were supplemented by an exhibition of working experimental equipment on an unprecedented scale.

The first of these three books provides the edited proceedings of this part of the Second Geneva Conference. It is divided into surveys of progress in the chief countries working in this field, followed by reviews of the main experimental devices, the Stellarator, the magnetic mirror, the plane shock and the pinched discharge.

These are succeeded by a series of more general theoretical papers on plasma physics and finally by proposals from the U.S.S.R. and the United States for more esoteric methods of stabilizing hot plasma, such as the Astron.

Valuable though this collection is, the papers are not easy reading; hence the second book, by Prof. Allis, which is successful in providing most of the information in a more easily digested form, is welcome.

The third work, by Glasstone and Lovberg, carries the process of digestion still further, and is an excellent advanced introduction to the whole subject. It is a graduate text-book carefully thought out to meet the needs of experimentalists rather than of theoreticians, though theoreticians will find it a valuable guide through the thicket of experimental results and devices. Particularly good is the second chapter. Here are discussed the physical conditions which have to be met for thermonuclear reactions to occur at all, as well as those needed to achieve a net gain of power in any practical device.

It is now clear that the difficulties in the way of the attainment of economic power by fusion of the isotopes of hydrogen are formidable. The fuel (deuterium gas or a deuterium-tritium mixture) must be confined in a space isolated from material walls and maintained in the ionized state at an extremely high temperature (some tens or hundreds of millions of degrees) for recurrent periods each lasting about a second. In nearly all proposals this confinement involves the use of powerful magnetic fields and in the forms most worked with-the simple pinch and the Stellarator-they have so far been found to fail because the confined plasmas are basically unstable. Instabilities may take several forms ; to discover means of curbing them calls for a much deeper understanding of their nature than exists at present, and of the way they build up from small perturbations to large disturbances and so cause the plasma to escape.

The authors deal in as clear a way as seems possible to-day with this matter, as well as with radiation losses from a very hot plasma, including 'cyclotron' radiation-loss at high temperatures, a spectre raised by Russian workers two years ago and not yet fully laid.

In his foreword to the book, Dr. A. E. Ruark expresses the hope that it will command the respect and gratitude of a world-wide audience. $\mathrm{He}$ can be assurod that it will.

These three works show that the achievement of economical controlled thermonuclear power presents an exceptional scientific and technical challenge, one so difficult that it may indeed never be possible to meet. It is far too early to be pessimistic about the outcome of this great enterprise, but it is now clear that success will not be easily attained nor will progress be so rapid as with power from nuclear fission.

BASIL SchONLAND

\section{CARBOHYDRATE CHEMISTRY}

The Carbohydrates

By S. F. Dyke. (The Chemistry of Natural Products, Vol. 5.) Pp. v + 232. (New York: Interscience Publishers, Inc.; London : Interscience Publishers, Ltd., 1960.) $36 s$.

$\Gamma$

HIS book is one of a series of monographs designed to supplement the general text-book of organic chemistry with more detailed descriptions of the main groups of natural products. It gives a balanced account of the various facets of carbohydrate chem. istry, and the text is adequately supplied with references to reviews and original papers. The author assumes little or no previous knowledge of the subject, but the treatment is sometimes sketchy and some of the material is presented in the form of notes with little commentary. One feels that the student would have been better sorved 